\section{Research Square}

Preprints are preliminary reports that have not undergone peer review.

They should not be considered conclusive, used to inform clinical practice, or referenced by the media as validated information.

\title{
Study on Tidal Volume According to the 4-Point Sealing Forces of Bag-Valve- Mask : An Adult Respiratory Arrest Simulator Based Prospective, Descriptive Study
}

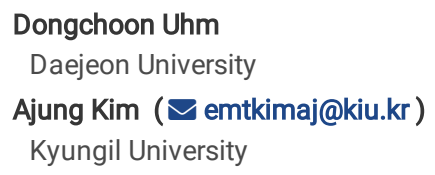

\section{Research Article}

Keywords: respiratory, ventilation, C shape, BVM

Posted Date: February 26th, 2021

DOI: https://doi.org/10.21203/rs.3.rs-242965/v1

License: () (1) This work is licensed under a Creative Commons Attribution 4.0 International License. Read Full License 


\section{Abstract \\ Background}

For adequate ventilation during bag-valve-mask ventilation, rescuers should ensure a proper mask seal using the one-handed or two-handed technique. Little is known how much sealing forces of bag-valve-mask are needed for adequate ventilation. This study aimed to explored the effect of the 4-point sealing forces of a bag-valve-mask on tidal volume while using the one-handed technique, focusing on the moderating effect of $\mathrm{C}$ length ( $\mathrm{C}$ length is the distance from the thumb to index finger in the $\mathrm{C}$ shape of in the one-hand $\mathrm{EC}$ grip).

\section{Methods}

This was a prospective, descriptive simulation study design. Convenience sample of 125 undergraduate paramedic students from two universities was participated. A self-reported questionnaire was used to collect subject data. Tidal volumes, 4-point sealing forces of the mask, peak pressure, and C length of the $\mathrm{C}$ shape in the one-hand EC grip, were measured using the mechanical lung model under a simulated adult respiratory arrest. Hierarchical regression analysis was used to determine the moderating effect of $\mathrm{C}$ length on tidal volume in bag-valve-mask ventilation.

\section{Results}

The average $C$ length, peak pressure and tidal volume were $7.54( \pm 1.85) \mathrm{cm}, 11.62( \pm 5.40) \mathrm{cmH} 20$, and $321.66( \pm 135.18) \mathrm{mL}$, respectively. The average range of the 4-point sealing forces were 0.03-0.69 newton. The apex sealing force was the weakest point among the 4-point sealing forces. Hierarchical regression analysis demonstrated that tidal volume accounted for $62.7 \%$ of the variance by $C$ length, peak pressure, and apex sealing force during bag-valve-mask ventilation $(F=9.676, p<.001)$. $C$ length moderated the effect of apex sealing force and peak pressure on tidal volume. That is, the more peak pressure and apex sealing force, the more the tidal volume, and the longer the $\mathrm{C}$ length, the more the tidal volume.

\section{Conclusion}

We developed effective advice that can be adopted in clinical practice without side effects as the first simulation study measuring the 4-point sealing forces during bag-valve-mask ventilation, as well as underpin continuous retraining and assessment that focus on individual physical characteristics, such as $\mathrm{C}$ length and bag-valve-mask sealing force.

\section{Background}

Bag-valve-mask (BVM) ventilation is standard for cardiopulmonary arrest, as well as emergency airway management in cases where spontaneous breathing is failing or has ceased, regardless of place or time. The ability of rescuers to deliver adequate BVM ventilation is considered relatively simple task, but it is an important and challenging skill that requires considerable practice. The adequate ventilation is to deliver each rescue breathing over 1 second to give a sufficient tidal volume, using the BVM, to produce a visible chest rise (1). This is deeply associated with the survival rate as well as oxygenation of patients with cardiac or respiratory arrest (2). Excessive ventilation, however, results in significantly increased intrathoracic pressure and decreased coronary perfusion pressures and survival rates $(3,4)$. Rescuers seal the mask against the face using either one- or two-handed techniques, with the thumb and index finger wrapped in a " C "shape around the mask apex, and the remaining fingers in an "E" shape, lifting the jaw (5); this is called the "EC grip". Successful ventilation via the EC grip can be achieved by creating a tight seal between the mask and face and squeezing the bag with reasonable force (6). Several previous studies (7-13) have reported that the BVM tidal volume delivered is affected by rescuers' squeezing methods, as well as individual characteristics such as gender, height, weight, hand width and length, grip power, education, practice, experience etc.; however, reported results are inconsistent.

The most important aspect of air leaking prevention during BVM ventilation is the perfect seal between the mask and patient's face, generated by the sealing force of the mask toward the patient's face during the EC grip. Few studies have explored the relationship between BVM ventilation and sealing force in South Korea; therefore, the purpose of this study was to identify the factors affecting the tidal volumes with respect to the 4-point sealing forces of BVMs, with a focus on the moderating effects of C length, using a RespiTrainer® Advance manikin and Quick Lung®.

\section{Material And Methods Study design}

This was a prospective, descriptive study that simulated adult respiratory arrest using a mechanical lung model.

\section{Participants and setting}

To ensure an adequate sample size, we performed a power analysis using G Power 3.1.5 (SOFTMEDIA) program; the desired sample size for a computation of test power (1- $\beta$ ) of 0.80 with 17 predictors was 146 , with an effect size of 0.15 and alpha of 0.05 . After contacting the directors of two universities from a big city in South Korea to obtain permission for recruitment, a convenience sample of 160 undergraduate paramedic students from two universities was recruited; 35 students dropped out due to personal reasons, such as part time jobs or family events. Finally, 125 questionnaires were used in the analysis; participation was both voluntary and anonymous. The inclusion criterion was right-handed individuals who had completed the cardiopulmonary resuscitation (CPR) theory and practical course in accordance with the 2015 American Heart Association (AHA) guidelines.

Page 2/11 


\section{Measurements and procedures}

Measurements in this study consisted of both subjective and objective variables. Subjective variables were measured using the self-reported questionnaire, which included general characteristics, knowledge, and confidence performing the BVM ventilation technique for respiratory arrest patients; this took approximately 10 minutes to complete. Data collection of objective variables, such as tidal volume (TV), peak pressure (PP), C length, and 4-point sealing forces of the mask, took about 5 minutes per participant.

\section{Subjective variables}

\section{General characteristics}

General characteristics of interest included gender, school year, academic grade, clinical practice satisfaction, major satisfaction, experience in the BVM ventilation of respiratory arrest patients, acquired certificates, and body mass index $\left(\mathrm{BMI}, \mathrm{kg} / \mathrm{m}^{2}\right)$.

\section{Knowledge}

Knowledge regarding BVM ventilation was assessed using a previously published scale (14). The questionnaire comprised ten items; a correct response was scored 1. The total score ranged from 0 to 10; high scores indicated more knowledge regarding BVM ventilation. The Kuder-Richardson Formula 20 was 0.69 in a previous study (14), and 0.68 in the present study.

\section{Performance confidence}

The scale used to assess performance confidence was developed in a previous study (14). The questionnaire comprises ten items, each rated on a five-point Likert scale ranging from "strongly disagree" (1), to "strongly agree" (5). High scores indicated a higher level of performance confidence. Cronbach's alpha in the previous study (14) was 0.90 , and 0.93 in the present study.

\section{Objective variables}

The objective variables in this study included TV, PP, C length, and 4-point sealing forces of the mask. All participants were asked to hold the mask with their left hand, and the bag with their right hand; data collection took about 5 minutes per participant.

\section{Experimental environment}

\section{TV and PP}

A RespiTrainer® Advance manikin (IngMar Medical, Ltd., Pittsburgh, PA, USA) was placed at the same height as the participants' middle femur line (15, 16), using the foothold to adjust the height. A Quick Lung® (IngMar Medical) and personal digital assistance were connected to the manikin, and data were sent to the personal digital assistance through its embedded device. The Quick Lung® was set with compliance of $50 \mathrm{~mL}^{\circledR} \cdot \mathrm{cmH}_{2} \mathrm{O}^{-1}$ and resistance of $5 \mathrm{cmH} \mathrm{H}_{2} \mathrm{O} \cdot \mathrm{L}^{-1} \cdot \mathrm{S}$ based on previous studies $(17,18)$. Participants were instructed to use a BVM $(1600 \mathrm{~mL}$, Ambu Mark 囚- Reusable Resuscitator with silicon face mask size 5 ; Ambu, Copenhagen, Denmark) to ventilate the manikin, simulating an adult with respiratory arrest, for two minutes (measured using a metronome (10 times/min)). BVM ventilation was performed while standing without chest compression and oral or nasal airway; i.e., the left hand secures the mask on the manikin's face using the "EC" grip, while the right hand holds the bag comfortably. Before data collection, participants were given the opportunity to practice ventilation for two minutes to familiarize themselves with the study setting. Study participants were blinded for the study purpose. The average TV ( $\mathrm{mL}$ ) and PP (cmH2O) were collected and calculated for each participant.

\section{Apex, bottom, left, and right sealing forces of the mask in C shape of EC grip}

The 4-point forces of the mask in the EC grip are the apex, bottom, left, and right sealing forces. To measure the sealing forces in the $\mathrm{C}$ shape of the EC grip, sensors were attached to four points where the mask touches the manikin's face (Fig. 1). Four 0.5" Circles (Part No. 402) of Interlink Force

Sensing Registors ${ }^{\circledR}$ (Interlink Electronics, Inc, Camarillo, California, United States) were installed for force measurement; the force data (N) collected from the sensor were coded and calculated through ARDUINO Software (https://www.arduino.cc/en/main/software).

\section{C length}

The $\mathrm{C}$ length $(\mathrm{cm})$, defined as the distance from the thumb to index finger in the $\mathrm{C}$ shape of the "EC" grip, was measured using a distance measuring application from AGUMON LAB (20). First, a picture was taken of the EC shaped hand that held the BVM. A reference object was then selected for length measurement (the reference object for this study was a 1,000 won Korean bill; Fig. 2), and the start and end points of the reference object were selected. Finally, the length was measured after the start and end points of the reference object were fitted to the thumb and index fingers in the picture.

\section{Statistical analysis}

Data was analyzed using IBM SPSS Statistics for Windows, Version 26.0 (SPSS Inc., Chicago, IL, USA). To confirm normal distribution of the data, the kurtosis and skewness were confirmed. Logarithmic and squared transformation was applied on apex sealing force data; those kurtosis and skewness were less than the standard of normality (skewness $<3$, kurtosis $<10$ ). Statistical analyses were performed via descriptive statistics, Pearson's correlation analysis, and hierarchical regression analysis. To verify the moderating effects of $\mathrm{C}$ length on tidal volumes, general characteristics and subjective variables (knowledge, performance confidence) were adjusted (controlled), and hierarchical regression analysis was performed to confirm the influence of the predictors. Mean centering was used to remove multicollinearity among predictor variables (PP, apex sealing force, bottom sealing force, right sealing force, and left sealing 
force) and interaction variables (PP * $\mathrm{C}$ length; apex sealing force * $\mathrm{C}$ length; bottom sealing force * $\mathrm{C}$ length; right sealing force * $\mathrm{C}$ length; left sealing force * $\mathrm{C}$ length). Additionally, to resolve the problem of multicollinearity, the independent and moderating variables were standardized. Control variables including gender, school year, academic grade, experience with BVM ventilation, and acquired certificate of general characteristics, were transformed into dummy code; continuous variables such as clinical practice satisfaction, major satisfaction, BMI, knowledge, and confidence performing BVM ventilation were used without transformation.

\section{Ethical considerations and data collection}

This study was conducted in accordance with the principles of the Declaration of Helsinki, and was approved by the relevant institutional review board Written, informed consent was obtained from all participants prior to conducting this study; participants were informed that they could withdraw their consent at any point during this study without consequences. Data were collected between November 4, 2019 and December 13, 2019.

\section{Results}

\section{General characteristics}

General characteristics are presented Table 1. Half of participants (53.6 \%) were female, while $43.2 \%$ and $8.0 \%$ were juniors and seniors during the school year, respectively; $67.2 \%$ had an academic grade between 3.0 and 3.99 . The mean scores regarding clinical practice and major satisfaction were 3.76 ( \pm 0.78 ) $4.07( \pm 0.76)$, respectively 
Table 1

General characteristics, subjective and objective variables $\mathrm{N}=125$

\begin{tabular}{|c|c|c|c|c|c|c|}
\hline \multicolumn{4}{|l|}{ Category } & \multirow{2}{*}{$\begin{array}{l}\mathbf{N} \\
58\end{array}$} & \multirow{2}{*}{$\begin{array}{l}(\%) \\
(46.4)\end{array}$} & \multirow[t]{2}{*}{ Mean $( \pm S D)$} \\
\hline \multirow[t]{17}{*}{ General characteristics } & \multirow[t]{2}{*}{ Gender } & \multicolumn{2}{|l|}{ male } & & & \\
\hline & & \multicolumn{2}{|c|}{ female } & 67 & $(53.6)$ & \\
\hline & \multirow[t]{4}{*}{ School year } & \multicolumn{2}{|c|}{ Freshman } & 31 & $(24.8)$ & \\
\hline & & \multicolumn{2}{|c|}{ Sophomore } & 30 & $(24.0)$ & \\
\hline & & \multicolumn{2}{|c|}{ Junior } & 54 & $(43.2)$ & \\
\hline & & \multicolumn{2}{|c|}{ Senior } & 10 & (8.0) & \\
\hline & \multirow[t]{3}{*}{ Academic grades } & \multicolumn{2}{|l|}{$4.0 \leq$} & 20 & $(16.0)$ & \\
\hline & & \multicolumn{2}{|c|}{$3.0-3.99$} & 84 & $(67.2)$ & \\
\hline & & \multicolumn{2}{|c|}{$2.99 \geq$} & 21 & $(16.8)$ & \\
\hline & \multicolumn{3}{|l|}{ Clinical practice satisfaction $(1-5)$} & & & $3.76( \pm 0.78)$ \\
\hline & \multicolumn{3}{|l|}{ Major satisfaction $(1-5)$} & & & $4.07( \pm 0.76)$ \\
\hline & \multirow[t]{2}{*}{ Experience of BVM ventilation } & \multicolumn{2}{|l|}{ No } & 69 & $(55.2)$ & \\
\hline & & \multicolumn{2}{|l|}{ Yes } & 56 & $(44.8)$ & \\
\hline & \multirow[t]{4}{*}{ Acquired certificate } & No & 0 & 59 & $(47.2)$ & \\
\hline & & Yes & 1 & 52 & $(41.6)$ & \\
\hline & & & 2 & 9 & $(7.2)$ & \\
\hline & & & 3 & 5 & $(4.0)$ & \\
\hline & $\mathrm{BMI}\left(\mathrm{kg} / \mathrm{m}^{2}\right)$ & & & & & $22.89( \pm 2.77)$ \\
\hline \multirow[t]{2}{*}{ Subjective variables } & Knowledge $(0-10)$ & & & & & $6.29( \pm 1.69)$ \\
\hline & Performance confidence $(10-50)$ & & & & & $36.89( \pm 6.80)$ \\
\hline \multirow[t]{7}{*}{ Objective variables } & C length $(\mathrm{cm})$ & & & & & $7.54( \pm 1.85)$ \\
\hline & Peak pressure $\left(\mathrm{cmH}_{2} \mathrm{O}\right)$ & & & & & $11.62( \pm 5.40)$ \\
\hline & In (apex sealing force) (N) & & & & & $0.03( \pm 0.03)$ \\
\hline & Bottom sealing force $(\mathrm{N})$ & & & & & $0.69( \pm 0.80)$ \\
\hline & Left sealing force $(\mathrm{N})$ & & & & & $0.53( \pm 0.46)$ \\
\hline & Right sealing force $(\mathrm{N})$ & & & & & $0.31( \pm 0.41)$ \\
\hline & Tidal volume (mL) & & & & & $321.66( \pm 135.18)$ \\
\hline
\end{tabular}

Experience in BVM ventilation was $44.8 \%$ of participants. Regarding acquired certificates such as the basic life support provider (BLS-P), Korea advanced life support provider (KALS-P), or advanced cardiovascular life support provider (ACLS-P), $52.8 \%$ of participants had obtained more than one certificate.

BMI was $22.89( \pm 2.77) \mathrm{kg} / \mathrm{m}^{2}$, while mean knowledge and performance confidence scores were $6.29( \pm 1.69)$ and $36.89( \pm 6.80)$, respectively. Average C length and PP were $7.54( \pm 1.85) \mathrm{cm}$ and $11.62( \pm 5.40) \mathrm{cmH}_{2} \mathrm{O}$, respectively. The 4-point sealing forces (apex, bottom, left, and right) in the $\mathrm{C}$ shape of the EC grip were $0.03( \pm 0.03) \mathrm{N}, 0.69( \pm 0.80) \mathrm{N}, 0.53( \pm 0.46) \mathrm{N}$, and $0.31( \pm 0.41) \mathrm{N}$, respectively; mean TV was $321.66( \pm 135.18) \mathrm{mL}$.

\section{Correlation among major variables}

Correlation among major variables are presented Table 2. TV had positive correlations with PP $(r=$

$0.744, p<0.001)$, right sealing force $(r=0.409, p<0.001)$, and acquired certificate $(r=0.299, p=0.001)$. In addition, apex sealing force $(r=0.246, p=0.06)$,

experience in BVM ventilation $(r=$ 
Table 2

Correlation among major variables

\begin{tabular}{|c|c|c|c|}
\hline Category & Variables & $r$ & $(p)$ \\
\hline \multirow[t]{7}{*}{ Objective variables } & Tidal volume & 1 & \\
\hline & C length & $-.223^{*}$ & $(.012)$ \\
\hline & Peak Pressure (PP) & $.744^{\star \star \star}$ & $(<.001)$ \\
\hline & In(apex sealing force) & $.246^{\star *}$ & $(.006)$ \\
\hline & Bottom sealing force & -.165 & $(.065)$ \\
\hline & Left sealing force & -.068 & $(.449)$ \\
\hline & Right sealing force & $.409^{\star \star *}$ & $(<.001)$ \\
\hline \multirow[t]{5}{*}{ General characteristics } & Clinical practice satisfaction & -.054 & $(.548)$ \\
\hline & Major satisfaction & .039 & $(.666)$ \\
\hline & Experience of BVM ventilation & $.230^{*}$ & $(.010)$ \\
\hline & Acquired certificate & $.299^{*}$ & $(.001)$ \\
\hline & BMI $\left(\mathrm{kg} / \mathrm{m}^{2}\right)$ & .100 & $(.269)$ \\
\hline \multirow[t]{2}{*}{ Subjective variables } & Knowledge & $.205^{*}$ & $(.022)$ \\
\hline & Performance confidence & .144 & $(.110)$ \\
\hline
\end{tabular}

$0.230, p=0.010)$, and knowledge $(r=0.205, p=0.022)$, were correlated. However, TV had a negative correlation with $C$ length $(r=-0.223, p=0.012)$.

\section{The moderating effects of $\mathrm{C}$ length in relation to tidal volumes and 4-point sealing forces of the BVM}

The results of the regression analysis on the moderating effects of $\mathrm{C}$ length are presented Table 3 . In the first step, hierarchical regression analysis was performed with general characteristics, subjective variables, PP, and 4-point sealing forces as independent variables to identify the effects of predictor variables on TV. PP and apex sealing force were significantly associated with the TV for Model 1, accounting for $59.7 \%$ of the explained variance in TV ( $F=$ $11.210, p<0.001)$. Second, $C$ length was added to Model 1 ; PP and apex sealing force were significantly associated with the TV that resulted in $59.6 \%$ of the explained variance in TV $(F=10.614, p<0.001)$. Finally, interaction variables were added to Model 2 to identify the moderating effects of $C$ length; among the interaction variables, $P P{ }_{\star} C$ length $(\beta=0.195, p=0.017)$ and apex sealing force ${ }_{*} C$ length $(\beta=0.154, p=0.014)$ were significantly associated with TV. Model 3 's equation resulted in $62.7 \%$ of the explained variance in TV $(F=9.676, p<0.001)$; i.e., C length was the variable found to have a moderating effect in the relationship between TV, PP, and apex sealing force. 
Table 3

Moderating effects of $\mathrm{C}$ length

\begin{tabular}{|c|c|c|c|c|c|c|c|c|c|c|c|c|c|c|}
\hline & \multicolumn{5}{|c|}{ MODEL \ } & \multicolumn{5}{|c|}{ MODEL \ } & \multicolumn{4}{|c|}{ MODEL 『 } \\
\hline & B & S.E. & $\beta$ & $\mathrm{t}$ & $p$ & $B$ & S.E. & $\beta$ & $\mathrm{t}$ & $p$ & $B$ & S.E. & $\beta$ & $\mathrm{t}$ \\
\hline (Constant) & 310.872 & 47.135 & & $6.595^{\star \star \star}$ & $<.001$ & 307.808 & 47.382 & & $6.496^{\star \star \star}$ & $<.001$ & 334.357 & 47.89 & & $6.9 \varepsilon$ \\
\hline PP & 100.495 & 10.254 & 0.743 & $9.800^{\star \star \star}$ & $<.001$ & 99.688 & 10.324 & 0.737 & $9.656^{\star \star \star}$ & $<.001$ & 94.404 & 10.149 & 0.698 & 9.36 \\
\hline $\ln (\mathrm{ASF})$ & 17.521 & 8.789 & 0.13 & $1.993^{*}$ & 0.049 & 18.055 & 8.832 & 0.134 & $2.044^{*}$ & 0.043 & 14.649 & 8.554 & 0.108 & 1.71 \\
\hline BSF & 6.5 & 10.192 & 0.048 & 0.638 & 0.525 & 6.342 & 10.212 & 0.047 & 0.621 & 0.536 & 4.327 & 9.856 & 0.032 & $0.4 i$ \\
\hline LSF & 4.409 & 9.854 & 0.033 & 0.447 & 0.655 & 3.907 & 9.892 & 0.029 & 0.395 & 0.694 & 2.139 & 9.583 & 0.016 & $0.2 \%$ \\
\hline RSF & -3.477 & 10.918 & -0.026 & -0.318 & 0.751 & -4.074 & 10.965 & -0.03 & -0.372 & 0.711 & -3.596 & 11.616 & -0.027 & -0.3 \\
\hline \multicolumn{15}{|l|}{ Gender } \\
\hline male & 11.739 & 18.759 & -0.043 & -0.626 & 0.533 & 13.801 & 18.976 & 0.051 & -0.727 & 0.469 & $2<.001$ & 18.86 & 0.007 & -0.1 \\
\hline \multicolumn{15}{|l|}{ School year } \\
\hline first & 2.92 & 58.543 & 0.106 & -0.562 & 0.575 & 27.907 & 58.996 & -0.09 & -0.473 & 0.637 & 73.986 & 59.456 & 0.237 & -1.2 \\
\hline second & 18.859 & 41.901 & 0.06 & 0.45 & 0.654 & 23.252 & 42.348 & 0.074 & 0.549 & 0.584 & -4.849 & 43.107 & -0.015 & -0.1 \\
\hline third & 57.199 & 45.923 & 0.21 & 1.246 & 0.216 & 61.172 & 46.284 & 0.225 & 1.322 & 0.189 & 22.461 & 46.958 & 0.083 & $0.4 i$ \\
\hline \multicolumn{15}{|l|}{$\begin{array}{l}\text { Academic } \\
\text { grades }\end{array}$} \\
\hline $4.0 \leq$ & -28.406 & 32.624 & -0.077 & -0.871 & 0.386 & -28.663 & 32.685 & -0.078 & -0.877 & 0.383 & -23.244 & 31.585 & -0.063 & -0.7 \\
\hline $3.0-3.99$ & -12.027 & 23.923 & -0.042 & -0.503 & 0.616 & -11.718 & 23.969 & -0.041 & -0.489 & 0.626 & -6.857 & 23.571 & -0.024 & -0.2 \\
\hline CPS & 3.311 & 9.89 & 0.024 & 0.335 & 0.738 & 2.246 & $\begin{array}{l}10 \\
<.001\end{array}$ & 0.016 & 0.225 & 0.823 & 7.509 & 9.872 & 0.055 & $0.7 t$ \\
\hline MS & 1.898 & 10.639 & 0.014 & 0.178 & 0.859 & 3.284 & 10.804 & 0.024 & 0.304 & 0.762 & -3.038 & 10.528 & -0.022 & -0.2 \\
\hline \multicolumn{15}{|l|}{ EBVNV } \\
\hline yes & 17.288 & 19.721 & 0.064 & 0.877 & 0.383 & 17.003 & 19.76 & 0.063 & 0.86 & 0.391 & 14.758 & 19.037 & 0.055 & 0.7 \\
\hline$A C$ & -7.255 & 14.701 & -0.054 & -0.494 & 0.623 & -6.416 & 14.766 & -0.047 & -0.435 & 0.665 & -15.33 & 14.527 & -0.113 & -1.0 \\
\hline $\mathrm{BMI}\left(\mathrm{kg} / \mathrm{m}^{2}\right)$ & -1.77 & 9.278 & -0.013 & -0.191 & 0.849 & -1.77 & 9.295 & -0.013 & -0.19 & 0.849 & 1.725 & 9.388 & 0.012 & $0.1 \varepsilon$ \\
\hline Knowledge & 12.99 & 9.535 & 0.096 & 1.362 & 0.176 & 12.142 & 9.613 & 0.089 & 1.263 & 0.209 & 11.123 & 9.273 & 0.082 & 1.2 \\
\hline $\begin{array}{l}\text { Performance } \\
\text { confidence }\end{array}$ & -4.618 & 9.465 & -0.035 & -0.488 & 0.627 & -5.982 & 9.64 & -0.045 & -0.621 & 0.536 & -2.116 & 9.422 & -0.016 & -0.2 \\
\hline C. & & & & & & -6.774 & 8.63 & -0.05 & -0.785 & 0.434 & -0.135 & 9.095 & -0.001 & -0.0 \\
\hline $\mathrm{PP} \times \mathrm{C}$. & & & & & & & & & & & 25.179 & 10.33 & 0.195 & $2.4 i$ \\
\hline $\ln (A S F) \times C$ & & & & & & & & & & & 20.637 & 8.287 & 0.154 & $2.4 !$ \\
\hline $\mathrm{BSF} \times \mathrm{C}$. & & & & & & & & & & & 5.286 & 9.198 & 0.035 & $0.5 i$ \\
\hline LSF×C. & & & & & & & & & & & -9.387 & 7.948 & -0.071 & -1.1 \\
\hline $\mathrm{RSF} \times \mathrm{C}$. & & & & & & & & & & & -20.306 & 13.815 & -0.129 & -1.4 \\
\hline & \multicolumn{5}{|c|}{$F=11.210^{\star \star \star}, R^{2}\left({ }_{\text {adj }} R^{2}\right)=.656(.597)$} & \multicolumn{5}{|c|}{$F=10.614^{* \star \star}, R^{2}\left({ }_{a d j} R^{2}\right)=.658(.596)$} & \multicolumn{4}{|c|}{$F=9.676^{* \star *}, R^{2}\left({ }_{a d j} R^{2}\right)=.699(.627)$} \\
\hline
\end{tabular}

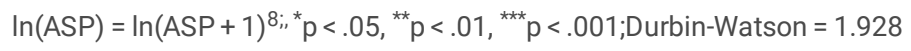

$\mathrm{PP}=$ Peak pressure, $\mathrm{ASF}=$ Apex sealing force, $\mathrm{BSF}=$ Bottom sealing force, $\mathrm{LSF}=$ Left sealing force, $\mathrm{RSF}=$ Right sealing force, $\mathrm{CPS}=\mathrm{Clinical}$ practice satisfact Major satisfaction, EBVNV = Experience of BVM ventilation, $A C=$ Acquired certificate, $C .=C$ length

\section{Discussion}

Focusing on $\mathrm{C}$ length, this study aimed to identify the factors affecting the TV via the 4-point sealing forces of the mask in BVM ventilation, using the onehanded technique, among undergraduate paramedic students from two universities in South Korea. Regression analysis of the moderating effects of $\mathrm{C}$ length revealed moderation of the effects of apex sealing force and PP on TV. Thus, the greater the PP and apex sealing force, the greater the TV; likewise, the longer the $\mathrm{C}$ length, the greater the TV. 
The average $\mathrm{C}$ length in this study was $7.54 \mathrm{~cm}$, with a longer $\mathrm{C}$ length being associated with a greater TV; however, a previous study (22) reported that the OE grip, where the distance from the thumb to the index finger is $0 \mathrm{~cm}$, provided more TV than the EC grip. Traditionally, the EC grip has been recommended for effective BVM ventilation by the AHA guidelines. The $\mathrm{C}$ length measured as a variable affecting TV in this study, but that was considerably different from previous studies $(7,8,10,11,24)$ that measured the hand length (distance from the middle edge of the palm to the distal thumb) and width (distance from the middle fingertip to the distal skin crease at the wrist) as TV-related variables. It is difficult to compare the results of these previous studies with those of the current study, as the measurement criteria for hand size differed. Nevertheless, BVM ventilation is traditionally performed by EC grip; in addition to the other variables, $\mathrm{C}$ length may be a significant determinant of TV and hence, successful bagging.

PP is the highest level of pressure applied to the lungs during inhalation. A previous study (25) reported that PP $>20 \mathrm{cmH} 20$ resulted in adverse effects such as gastric insufflation. In this study, the average PP was $11.62 \mathrm{cmH} 20$, lower than that from a previous study (13); however, this was higher than the 8.71 $\mathrm{cmH} 20$ previously reported (17). PP is directly proportional to TV; low PP was associated with suboptimal TV (321.6 mL) in this study.

The average range of the 4-point sealing forces was $0.03-0.69 \mathrm{~N}$.

There are no previous studies measuring mask sealing force in BVM ventilation; this is the first simulation study measuring the 4-point sealing forces in BVM ventilation as a variable affecting TV. We believe that the mask sealing force results provide a hypothesis for future studies, as the apex sealing force was the weakest among the 4-point sealing forces in this study. It may be that the upward pressure of the three fingers, forming the letter " $E$ " on the inferior of the mandible to hold the mask to the face, was stronger than the downward pressure of the thumb and forefinger, forming " $\mathrm{C}$ " shape in the 1-handed technique, on the mask. In-depth future studies are needed to confirm whether the apex sealing force is 10 times lower than the sealing force of the other three points. Previous studies $(8,11)$ on the effect of hand grip strength on BVM ventilation were inconsistent. The results of this study suggest more technicalities than those of previous studies. For the development of effective BVM ventilation, continuous research on sealing force in various clinical situations is needed.

The average TV $(321.6 \mathrm{~mL})$ in this study was comparable with that of a previous study (24); participants in this study did not achieve the adequate TV, even though they had completed the CPR theory and practical courses in accordance with the AHA guidelines. We are not certain whether this result is related to the ability to perform the procedure, or due to lack of proper education; however, the evaluation of whether students have done well is as important as the education, and the AHA BLS-HP course does not provide feedback regarding BVM ventilation. Although simple, BVM ventilation is an important technique of emergency airway management that requires skill; therefore, ongoing education and training is necessary to enhance the effective sealing technique, creating a tighter seal between the mask and face, of paramedic students who will work in the prehospital stage.

\section{Limitations}

First, a manikin model was used instead of humans; although the manikin model allowed us to test our study in a highly controlled and consistent environment, it is unclear whether the same results would be achieved in patients. Second, the results of this study may not extend to all cases of BVM ventilation, as we only selected participants through convenience sampling. Additionally, this study did not use nasal or oral airways and did not consider the patient's facial characteristics.

\section{Conclusions}

As the first simulation study measuring the 4-point sealing forces in BVM ventilation, we believe that the results of this study suggest a new criteria for effective BVM ventilation in clinical practice and future research. The continuous retraining and assessment that focus on individual physical characteristics, such as $\mathrm{C}$ length and bag-valve-mask sealing force are also needed.

\section{List Of Abbreviations}

American Heart Association, AHA

Bag-valve-mask, BVM

Cardiopulmonary resuscitation, CPR

Peak pressure, PP

Tidal volume, TV

\section{Declarations}

\section{Ethics approval and consent to participate:}

All participating students received written and verbal information about the purpose and process of the study before launching the study. Participation was voluntary. All participating students provided written consent. This study was approved by the institutional review board of Daejeon University (104067-

201611-HR-008-02).

\section{Consent for publication:}

Not applicable. (All data was recorded anonymously and does not allow inference to the participating students.) 
Availability of data and materials:

The datasets used and analyzed during this study are available from the corresponding author on reasonable request.

Competing interests: The authors declare there was no conflict of interest.

Funding: This research was supported by Daejeon University funds (2020).

Authors' contributions: The two authors were involved in the entire process of this research, including conception and design of the study, literature search, analysis and interpretation of data, drafting and final approval of the version submitted.

Acknowledgments: We wish to thank the participants of this study, as well as Drs. Hoe-Hwan Jeong and Jeong-Ju Lee for providing corrections to early drafts of the manuscript.

\section{Authors' information:}

\section{Affiliations}

Department of Emergency medical technology, Daejeon University, 62 Daehak-ro, Dong-gu , Daejeon 300-716, Republic of Korea

Dongchoon Uhm

Department of Emergency Medical Technology, Kyungil University, 50,Gamasil-gil, Hayang-eup Gyeongsan-si, Gyeongbuk, 38428, Republic of Korea

Ajung Kim

\section{References}

1. Kleinman ME, Brennan EE, Goldberger ZD, Swor RA, Terry M, Bobrow BJ, et al. Part 5: Adult Basic Life Support and Cardiopulmonary Resuscitation Quality. 2015 American Heart Association Guidelines Update for Cardiopulmonary Resuscitation and Emergency Cardiovascular Care. Circulation. 2015;132:S41435.

2. Young P, Pilcher J, Patel M, Cameron L, Braithwaite I, Weatherall M, et al. Delivery of titrated oxygen via a self-inflating resuscitation bag. Resuscitation. 2013;84:391-4.

3. Aufderheide TP, Sigurdsson G, Pirrallo RG, Yannopoulos D, McKnite S, von Briesen C, et al. Hyperventilation-induced hypotension during cardiopulmonary resuscitation. Circulation. 2004;109:1960-5.

4. Aufderheide TP, Lurie KG. Death by hyperventilation: A common and life-threatening problem during cardiopulmonary resuscitation. Crit Care Med. 2004;32:S345-51.

5. Brown CA, Sakles JC, Mick NW. The walls manual of emergency airway management. 4th ed. 2018. USA: Wolters Kluwer.

6. Ortega R, Mehio AK, Woo A, Hafez DH. Positive-Pressure Ventilation with a Face Mask and a Bag-Valve Device. N Engl J Med. 2007;357:e4.

7. Lee HM, Cho KH, Choi YH, Yoon SY, Choi YH. Can you deliver accurate tidal volume by manual resuscitator? Emerg Med J. 2008;25:632-4.

8. Na JU, Han SK, Choi PC, Cho JH, Shin DH. Influence of face mask design on bag-valve-mask ventilation performance: a randomized simulation study. Acta Anaesthesiol Scand. 2013;57:1186-92.

9. Nehme Z, Boyle MJ. Smaller self-inflating bags produce greater guideline consistent ventilation in simulated cardiopulmonary resuscitation. BMC Emerg Med. 2009;9:4.

10. Otten D, Liao MM, Wolken R, Douglas IS, Mishra R, Kao A, et al. Comparison of bag-valve-mask hand-sealing techniques in a simulated model. Ann Emerg Med. 2014;63:6-12.e3.

11. Khoury A, Sall FS, De Luca A, Pugin A, Pili-Floury S, Pazart L, et al. Evaluation of Bag-Valve-Mask Ventilation in Manikin Studies: What Are the Current Limitations? Biomed Res Int. 2016;2016:4521767.

12. Halpern P, Dang T, Epstein Y, Van Stijn-Bringas Dimitriades D, Koenig KL. Six Hours of Manual Ventilation With a Bag-Valve-Mask Device Is Feasible and Clinically Consistent. Crit Care Med. 2019;47:e222-e6.

13. Zecha-Stallinger A, Wenzel V, Wagner-Berger HG, von Goedecke A, Lindner KH, Hormann C. A strategy to optimise the performance of the mouth-to-bag resuscitator using small tidal volumes: effects on lung and gastric ventilation in a bench model of an unprotected airway. Resuscitation. 2004;61:69-74.

14. Uhm DC, Kim AJ. Factors influencing performance confidence in paramedic students by knowledge and experience of respiratory-assistant therapy. Korean J Emerg Med Ser. 2018;22:67-77.

15. Uhm TH, Jung HK. Comparison of cardiopulmonary resuscitation quality using the over-the-head and lateral conventional positions with a bag-valvemask device performed by a single rescuer: A manikin study. Korean J Emerg Med Ser. 2016;20:7-15.

16. Hong JY, Oh JE, Kim CW, Kim SE, Lee HD, Shin JH. Effects of bed height on the performance of endotracheal intubation and bag mask ventilation. Signa Vitae. 2016;12:47-51.

17. Shin SY, Lee JG, Roh SG. Comparative analysis of tidal volume and airway pressure with a bag-valve mask using RespiTrainer. Fire Sci Eng. 2014;28:7681. 
18. Jo SM, Jung HK. Differentiation of tidal volume \& mean airway pressure with different Bag-Valve-Mask compression depth and compression rate. Korean J Emerg Med Ser. 2012:16:67-74.

19. Arduino IDE 1.8.13. https://www.arduino.cc/en/main/software.

20. Han Byeong-Length, Two-Headed Measurement App. https://play.google.com/store/apps/details?id=com.mainpage\&hl=ko

21. Matioc AA. The adult ergonomic face mask concept: historical and theoretical perspectives. J Clin Anesth. 2009;21:300-4.

22. Nam JL, Baek ML. Comparison of ventilation effects by mask-sealing methods during bag-valve-mask ventilation. Korean J Emerg Med Ser. 2018;22:7382.

23. Khoury A, Hugonnot S, Cossus J, De Luca A, Desmettre T, Sall FS, et al. From mouth-to-mouth to bag-valve-mask ventilation: evolution and characteristics of actual devices-a review of the literature. Biomed Res Int. 2014;2014:762053.

24. Lee NJ, Baek ML. Comparison of ventilation effects by mask-sealing methods during bag-valve-mask ventilation. Korean J Emerg Med Ser. 2018;22:7382.

25. Ho-Tai LM, Devitt JH, Noel AG, O’Donnell MP. Gas leak and gastric insufflation during controlled ventilation: face mask versus laryngeal mask airway. Can J Anaesth. 1998;45:206-11.

26. Peak inspiratory pressure. https://en.wikipedia.org/wiki/Peak_inspiratory_pressure.

27. Laffey JG, Bellani G, Pham T, Fan E, Madotto F, Bajwa EK, et al. Potentially modifiable factors contributing to outcome from acute respiratory distress syndrome: the LUNG SAFE study. Intensive Care Med. 2016;42:1865-76.

28. Guervilly C, Forel JM, Papazian L. Respiratory rate and peak inspiratory pressure, new targets from the LUNG SAFE study analysis or physiopathological artifacts? J Thorac Dis. 2017;9:225-7.

\section{Figures}

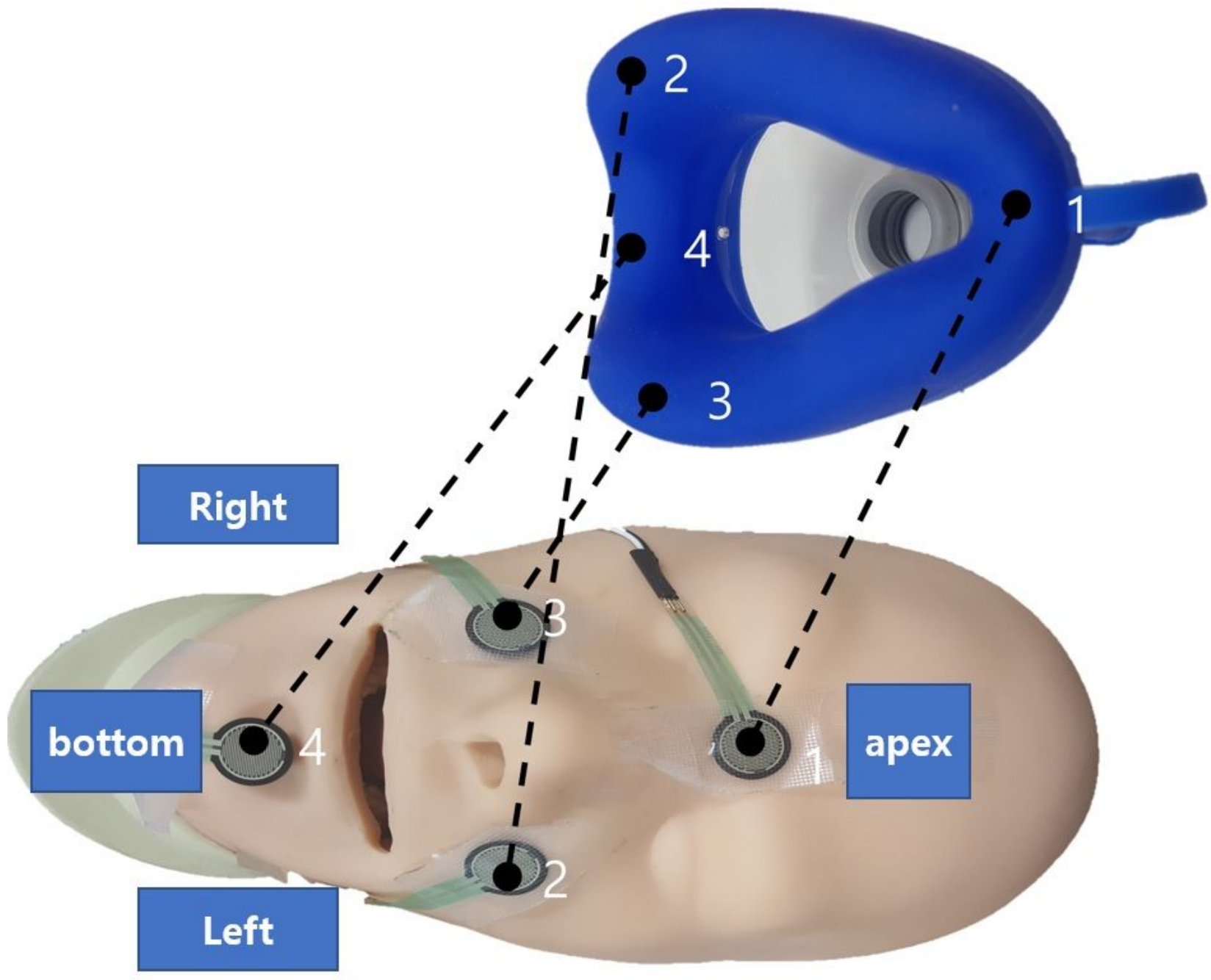

\section{Figure 1}

The 4-point forces of the mask in the EC grip are the apex, bottom, left, and right sealing forces. To measure the sealing forces in the $\mathrm{C}$ shape of the EC grip, sensors were attached to four points where the mask touches the manikin's face (Figure 1). Four 0.5" Circles (Part No. 402) of Interlink Force 


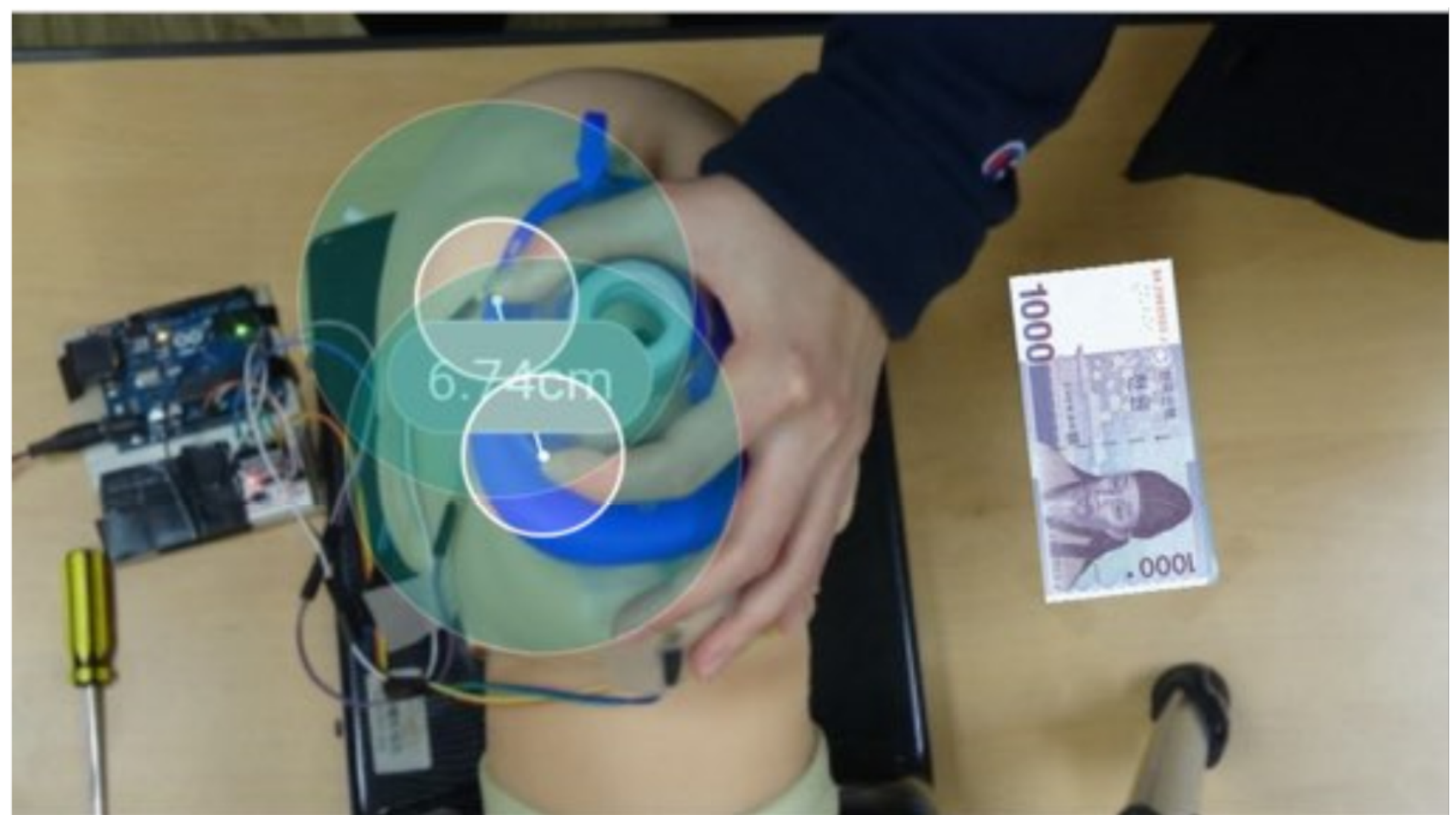

\section{Figure 2}

The $\mathrm{C}$ length $(\mathrm{cm})$, defined as the distance from the thumb to index finger in the $\mathrm{C}$ shape of the "EC" grip, was measured using a distance measuring application from AGUMON LAB (20). First, a picture was taken of the EC shaped hand that held the BVM. A reference object was then selected for length measurement (the reference object for this study was a 1,000 won Korean bill; Figure 2), and the start and end points of the reference object were selected. Finally, the length was measured after the start and end points of the reference object were fitted to the thumb and index fingers in the picture 